\title{
Himalayan Tectonic Belt: Morlet Wavelet Variation and Seismic Harmony
}

\author{
Yebang $\mathrm{Xu}^{1}$ and Paul W. Burton ${ }^{1}$
}

\begin{abstract}
Morlet wavelet analysis is a method of studying the periodic spectrum of non-stationary physical signals and is applied to the Himalayan Tectonic Belt to explore whether there is any seismic periodicity, and to explore the possibility of harmony or commonality of properties among the seismic activities of different zones. The earthquake sequence during 1951-2016 with magnitudes $\mathrm{M} \geq 6.0$ is analysed. Wavelet non-periodicity for the Centre zone suggests a non-uniform spatial-temporal distribution of earthquake movement between plates which may relate with the rare great earthquakes, while the periodicities for the west and east zones may suggest the concurrence with the adjustment of the tectonic movement of the east- and west-end regions of the Himalayan Tectonic Belt relative to its central core. These three zones collectively form the Himalayan Tectonic Belt. This contains a periodicity of about five years of seismic activity that tests successfully with a $95 \%$ confidence statistic. Borrowing from the concept of musical harmony, this is the significant seismic harmonic which reflects the Belt's pervasive tectonic stress and an overall harmony of continent-continent plate convergence. Morlet wavelet analysis also reveals the Himalayan Tectonic Belt and the Pamir-Hindu Kush Tectonic Zone to be engaged as a big new family: the Himalayan Tectonic Belt Plus. It is demonstrated that this new whole also has seismic harmony with the common property again being the 5 -year periodicity. This indicates a unified structure of pervading active stress and seismic harmony permeating the overall seismicity.
\end{abstract}

Keywords: Himalaya tectonic belt, Pamir-Hindu Kush tectonic zone, earthquake, seismicity, Morlet wavelet, seismic harmony.

\section{Introduction}

The Himalayan Tectonic Belt is one of the most important plate boundaries in the world (Fig. 1). The Indian plate underthrusts northward beneath the Eurasian plate. The convergence generates numerous earthquakes, and this makes the belt one of the most

1 School of Environmental Sciences, University of East Anglia, Norwich NR4 7TJ, UK. E-mail: y.b.xu@uea.ac.uk seismically hazardous global regions (USGS, 2014). The seismic image of the structural belt is very complex. Exploring patterns of seismic activity, exploring whether there are periodicities in the seismic activity of single, adjacent and of combined zones should provide insights into any overarching harmony of seismic activity.

Elsewhere we have attempted to describe temporal and spatial patterns and fabrics of seismicity by adopting Cox, fractal and Hurst models of the seismic process (e.g. Xu, 1992; Xu \& Burton, 1997, 1999, 2006, 2014) and extended methods to earthquake early warning for protection of sensitive installations (Xu et al., 2003). In this study we seek to find direct discernment of periodicities in earthquake sequences by adopting wavelet analysis (Grossman \& Morlet, 1984). Wavelet analysis is a method of studying the periodic spectrum of non-stationary seismic signals and is a powerful tool to analyse localized variations of power within a geophysical time series. It decomposes a time series into timefrequency space, and from this the dominant modes of variability can be determined. The variations of these modes can also be identified (e.g. Torrence \& Compo, 1998). Morlet wavelets in particular have been used widely in geophysics, extending beyond seismology to, for example, palaeomagnetism. Lorito et al. (2003) used the Morlet wavelet approach to view the time evolution of the spectral content in paleomagnetic data series, particularly polarity excursions and reversals. Herein we focus on seismological examples.

A recent study into periodicity within global seismicity obtained observations which passed a statistical significance test (Yin et al., 2012). Yin et al. focussed on surface wave magnitude $M_{s} \geq 8.30$ earthquakes and using Morlet wavelets identified a 50 -year cycle in global seismicity with confidence 
well beyond 95\%, accompanied by lesser significant 80-100 years cycles of activity. The active component of the 50-year cycle lasts circa 10-14 years and a recent active cycle component was suggested for the years 2004-2018. At a different, much lower order of energy release, there are examples of time modulation of seismicity observed by Christiansen et al. (2007) for example, who demonstrated an annual seismicity period in the creeping segment of the San Andreas fault and semi-annual period in the locked segment. This seismicity consisted almost entirely of microearthquakes and the ultimate goal of

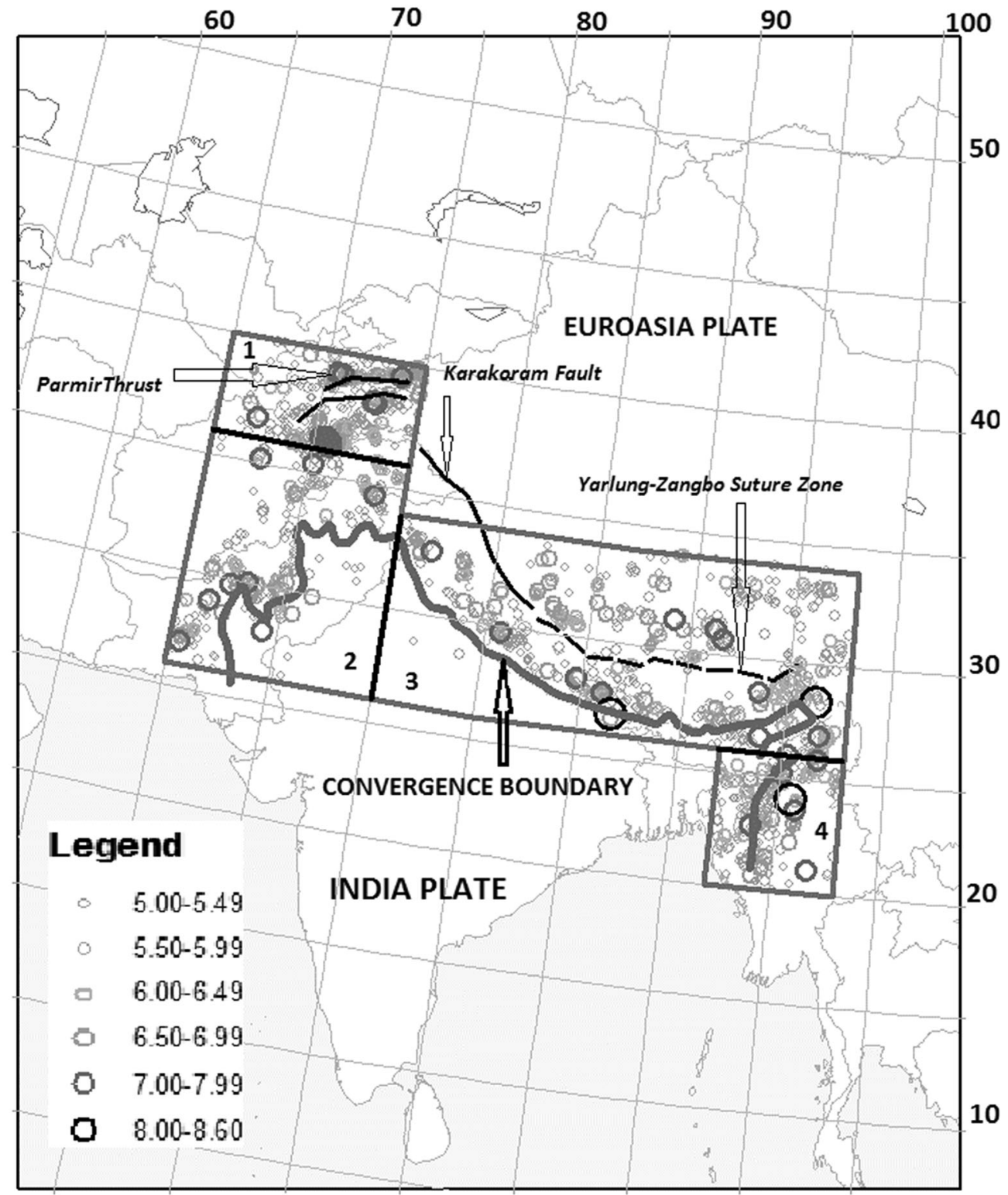

Figure 1

Distribution of strong earthquakes $(M \geq 5.0)$ between 1900 and January 2017 and the major seismic zones adopted for the Himalayan earthquake belt. Zones demarcated by the black lines and integers are (1) Pamir-Hindu Kush, (2) West, (3) Centre and (4) East. The heavy dark line is the convergence boundary. The dashed line is the Yarlung-Zangbo Suture Zone. The Pamir thrust and the Karakoram Fault are also shown on the map. Earthquake magnitudes are indicated by circles of increasing size as in the legend. Seismicity data are from the USGS 
research was the state of stress along the San Andreas fault, suggested to be influenced by the hydrologic cycle. Within our region of study Bollinger et al. (2007) observed a seasonal change in the number of recorded microearthquakes in the Himalaya of Nepal, there being about $37 \%$ fewer in summer than in winter. They strengthen their result by demonstrating a less than $1 \%$ probability of observing this periodic activity by chance-a mechanism is tentatively attributed to surface loading by summer monsoon rains. Both studies investigate periodicity in microearthquake seismicity of magnitude mostly $\mathrm{M} \leq 4.0$ and all are $\mathrm{M} \leq 6.0$. Other studies use magnitudes spanning from microearthquakes up to those with $M \geq 7.0$. There are several methodologies adopted. The strong and destructive earthquake history of Italy has been examined by Bragato (2017), using magnitudes $M \geq 6.0$ in the historical catalogue of Italy spanning 1600-2016. Bragato detects a 'marked periodicity of 46 years' using Schuster spectrum analysis, a modification of Schuster's (1898) approach to discerning periodicity with significance testing. We shall adopt magnitudes $M \geq 6.0$ for our study, like Bragato-see later. The seismicities of the Central San Andreas Fault near Parkfield, and the Sierra Nevada-Eastern California Shear Zone, both in Central California, have been examined by Dutilleul et al. (2015) using 30-year duration catalogues spanning 1980-2010: both zones exhibit periodicities of two months to several years; although the modelled results are complex. They adopt a 'multifrequential periodogram analysis', applied to time series of monthly earthquake numbers, to discern periodicities; rather than adopt modifications to Schuster's (1897) traditional method. In contrast we shall target strong earthquakes of magnitude $\mathrm{M}$ $\geq 6.0$, akin to Yin et al. (2012) for global great earthquakes with $\mathrm{Ms} \geq 8.3$, and like Bragato (2017) for regional destructive earthquakes $M \geq 6.0$, but in the Himalayan earthquake belt, and attempt to discern if relatively short periodicities exist within the seismicity, and if such periodicities are widespread in the seismicity-as clearly the entire regional seismotectonics are dominated by the plate tectonic mechanisms associated with continent-continent collision.
We set the scene with a brief description of the tectonics in the region and some major earthquakes that have been instrumentally recorded and entered the historical catalogue. The Himalayan Tectonic Belt consists of the West, Central and East zones marked 2, 3 and 4 in Fig. 1. The West zone comprises the foothills of the north-south trending Sulaiman Range (USGS, 2014). This zone is along the western margin of the Indian plate. Its main tectonic characteristics are: the Indian plate translates obliquely relative to the Eurasian Plate, resulting in a complex fold-boundary and thrust belt of the Sulaiman Range. In other words, the Himalayan tectonic belt extends to the west end in Nanga Parbat and turns into Pakistan where it digs deep inside the Eurasian plate with large impact (Den et al., 2014; USGS, 2014). There are strike-slip, reverse-slip and oblique-slip motions which have resulted in destructive earthquakes including four events during 1900-2015 of magnitude $\mathrm{M} \geq 7.5$ including the destructive Quetta earthquake of 1935 May $30(\mathrm{M}=7.5)$ which occurred in the Sulaiman Range and caused about 3500 deaths. Centre zone is the India-Euro plate boundary (USGS, 2014). This diffuse boundary lies within the limits of Yarlung-Zangbo Suture Zone to the north and the Main Frontal Thrust to the south. This narrow Himalaya Front contains numerous east-west trending parallel structures which exhibit the highest rate of seismicity and largest earthquakes in the Himalaya. This strong seismicity is caused mainly by movement on thrust faults. There have been five major events with $\mathrm{M} \geq 7.5$ during the years 1900-2016. Among these are two $M \geq 8.0$ earthquakes: at Bihar on 1934 January $15(\mathrm{M}=8.0)$ caused by reverse-slip fault movement and at Assam on 1950 August $15(\mathrm{M}=8.0)$ caused by right-lateral strike-slip fault movement. East zone consists of the India-Burmese Tectonic Arc area. Although there are deep earthquakes with depth exceeding $200 \mathrm{~km}$ due to the subduction of the eastwards-dipping India plate, the main seismicity is shallow earthquakes caused by occurrence of a combination of strike-slip and reverse faulting. In other words, the Himalayan tectonic belt extends to the east in Namche Barwa, turning to the Burma Arc, and deep into the interior of the Eurasian plate. Its impact is also very large (Den et al., 2014; USGS, 2014) with three large 
shallow events of $M \geq 7.5$, the largest of which occurred in Sagaing region, Burma on 1946 September 12 .

These three zones in the Himalayan tectonic belt have different activities and seismicity. This raises the following questions: What is the rhythm, cycle or periodicities of seismic activity in each zone? What are the differences between zones? What kind of rhythm and periodic characteristics are there in the Himalayan Tectonic Belt formed by these three zones? Are the characteristics shared across zones? Is it possible to reflect on the impact of a pervasive tectonic stress field? These topics will all be investigated by applying wavelet analysis.

In addition, in the Pamir-Hindu Kush Tectonic zone, deep earthquakes occur at depths $\geq 200 \mathrm{~km}$ beneath the Pamir-Hindu Kush Mountains (USGS, 2014). The big events caused by the remnant lithospheric subduction are evidenced by three large events with magnitude $M \geq 7.5$ which occurred in the period 1921-2015. There are also shallow crustal earthquakes which occurred near the Main Pamir Thrust, the main example of which is the magnitude $\mathrm{M}=7.5$ earthquake at a depth of $20 \mathrm{~km}$ in the Hindu Kush of Afghanistan on 1949 July 10.

Overall, the West, Central and East zones of Fig. 1 form the Himalayan Tectonic Belt. The PamirHindu Kush Tectonic zone is located on the northwestern edge of this belt and is characterised by lithospheric subduction. This zone has its own tectonic and seismicity characteristics, which are different to those of the Himalayan belt. However, there is a fundamental link between the Himalaya and the Pamir in terms of tectonic and plate activity as the Indian sub-continent pushes northward. Because of the connection, we refer to the Pamir-Hindu Kush Tectonic zone and the Himalayan Tectonic zone as the Himalayan Belt plus the Pamir-Hindu Kush Tectonic zone, or simply the Himalayan Tectonic Belt Plus. All these zones are contiguous, and all have internal stress fields attributable to continentcontinent collision. To what extent is their internal seismicity homogeneous, possessing a commonality of properties?

Here we include List of large earthquakes (Mw $\geq 7.0$ ) in the Himalayan and Pamir active tectonic belt (1900-2017 January) (Table 1) which occurred in our working area (Fig. 1). These 41 large earthquakes are rare events compared to the extremely large number of small and medium earthquakes that always occur in this huge active tectonic belt. But these large earthquakes collectively release a total of at least $1.01 \times 10^{25}$ Joules of coseismic energy (Eq. 2 and Table 1). Such a huge amount of energy! They should be typical events for this global giant tectonic active area.

In other words, the great earthquakes mentioned above are often considered to be what epitomises the seismicity of the Himalaya and Pamir earthquake activity-its seismicity. They are rightly famous earthquakes; they are rare and impressive; but they are not representative of what happens in Himalaya and Pamir seismicity for most of the time. What characteristics are representative and present most of the time in Himalaya and Pamir seismicity? The paper shall study the extent of this area as a homogeneous whole area, through attempting to find the Pamir's rhythmic features along with the characteristics for Himalayan seismic activity and to discern any commonalities between them.

\section{Data, Time Series of Square Root Coseismic Energy Release, and Cumulative Coseismic Energy Release: Implications}

The distribution of strong earthquakes $(M \geq 5.0)$ recorded instrumentally and located in the Pamir and Himalaya between 1900 and January 2017, along with major seismic zones selected for this study are shown in Fig. 1. Also indicated in the Figure are the convergence boundary, the Yarlung-Zangbo Suture Zone, the Pamir thrust and the Karakoram Fault. The earthquake record illustrated in Fig. 1 is provided by the USGS. This record for 50 years between 1900 and 1949 does not contain any $\mathrm{M}<6.0$ earthquake records. If the lower threshold of the magnitude were chosen as $M \geq 5$, it clearly would not be acceptable as a complete record for the intended purpose of analysis of strong earthquakes. Even with the $\mathbf{M}$ $\geq 6.0$ events, discussion of the completeness of the seismic data since 1900 for such a wide area, and the conditions of poor seismic recording and monitoring 
Table 1

List of strong earthquakes $(M w \geq 7.0)$ in the Himalayan and Pamir active tectonic belt (1900-2017 January). Main data sources: USGS, (2017) and CEA (1999)

\begin{tabular}{|c|c|c|c|c|c|c|c|c|}
\hline Year & Month & Day & $\begin{array}{l}\text { Latitude } \\
\mathrm{N}\end{array}$ & $\begin{array}{l}\text { Longitude } \\
\text { E }\end{array}$ & $\begin{array}{l}\text { Depth } \\
(\mathrm{km})\end{array}$ & $\begin{array}{l}\text { Magnitude } \\
(\mathrm{Mw})\end{array}$ & $\begin{array}{l}\text { Energy } \\
\times 10^{22} \mathrm{~J}\end{array}$ & Epicentre \\
\hline 1905 & 4 & 4 & 32.64 & 76.79 & 20.00 & 7.9 & 44.67 & India Kangra \\
\hline 1906 & 10 & 24 & 36.79 & 67.02 & 35.00 & 7.0 & 2.00 & Afghanistan, Balkh Province \\
\hline 1907 & 10 & 21 & 39.18 & 70.59 & 20.00 & 7.4 & 7.94 & Tajikistan \\
\hline 1908 & 12 & 12 & 26.95 & 96.77 & 15.00 & 7.0 & 2.00 & Myanmar, Kachin \\
\hline 1909 & 7 & 7 & 35.39 & 70.25 & 200.00 & 7.7 & 22.39 & Afghanistan, Nurestan \\
\hline 1909 & 10 & 20 & 28.07 & 69.33 & 35.00 & 7.0 & 2.00 & Pakistan, Sind Province \\
\hline 1911 & 2 & 18 & 38.33 & 72.63 & 15.00 & 7.3 & 5.62 & Tajikistan, Gorno-Badakhan Region \\
\hline 1912 & 5 & 23 & 21.04 & 96.74 & 15.00 & 7.5 & 11.22 & Myanmar, Shan State \\
\hline 1916 & 8 & 28 & 29.73 & 80.75 & 20.00 & 7.0 & 2.00 & Nepal, Mahakali Zone \\
\hline 1921 & 11 & 15 & 36.20 & 70.71 & 240.00 & 7.8 & 31.62 & Afghanistan, Badakhshan Province \\
\hline 1931 & 1 & 27 & 25.85 & 96.79 & 15.00 & 7.6 & 15.85 & Myanmar, Kachin State \\
\hline 1931 & 8 & 27 & 29.78 & 67.37 & 10.00 & 7.2 & 3.98 & Pakistan, Baluchistan Province \\
\hline 1934 & 1 & 15 & 26.89 & 86.59 & 15.00 & 8.0 & 63.10 & Nepal, Sagamatha Zone \\
\hline 1934 & 12 & 15 & 31.25 & 89.16 & 15.00 & 7.2 & 3.98 & China, Xizang, Xainza \\
\hline 1935 & 5 & 30 & 28.94 & 66.48 & 25.00 & 7.5 & 11.22 & Pakistan, Baluchistan \\
\hline 1938 & 8 & 16 & 22.75 & 93.92 & 75.00 & 7.0 & 2.00 & Myanmar, Chin State \\
\hline 1943 & 10 & 23 & 26.64 & 93.85 & 15.00 & 7.2 & 3.98 & India Assam \\
\hline 1946 & 9 & 12 & 24.05 & 95.67 & 15.00 & 8.0 & 63.10 & Burma Sagaing \\
\hline 1947 & 7 & 29 & 28.58 & 93.63 & 20.00 & 7.3 & 5.62 & India Arunachai Pradesh \\
\hline 1949 & 3 & 4 & 36.56 & 70.70 & 228.70 & 7.5 & 11.22 & Afghanistan Badakhshan Province \\
\hline 1949 & 7 & 10 & 39.17 & 70.89 & 20.00 & 7.5 & 11.22 & Tajik Districts of Repubican Subordination \\
\hline 1950 & 8 & 15 & 28.36 & 96.45 & 15.00 & 8.6 & 501.19 & India, Arunachai Pradesh \\
\hline 1951 & 11 & 18 & 31.06 & 91.26 & 30.00 & 7.7 & 22.39 & China, Xizang \\
\hline 1952 & 8 & 17 & 30.65 & 91.60 & 25.00 & 7.4 & 7.94 & China, Eastern Xizang \\
\hline 1956 & 6 & 9 & 35.16 & 67.61 & 25.00 & 7.3 & 5.62 & Afghanistan Baghlan Province \\
\hline 1965 & 3 & 14 & 36.41 & 70.72 & 207.80 & 7.4 & 7.94 & Afghanistan Badakhshan Province \\
\hline 1970 & 7 & 29 & 25.98 & 95.34 & 76.10 & 7.0 & 2.00 & Burma Sagaing \\
\hline 1974 & 8 & 11 & 39.46 & 73.83 & 9.00 & 7.3 & 5.62 & China Western Xinjiang \\
\hline 1983 & 12 & 30 & 36.37 & 70.74 & 214.50 & 7.4 & 7.94 & Afghanistan Hindu Kush \\
\hline 1985 & 7 & 29 & 36.19 & 70.90 & 98.70 & 7.4 & 7.94 & Afghanistan Kuran Wa Munjan \\
\hline 1988 & 8 & 6 & 25.15 & 95.13 & 90.50 & 7.3 & 5.62 & Burma Sagaing \\
\hline 1991 & 1 & 5 & 23.61 & 95.90 & 19.70 & 7.0 & 2.00 & Burma Sagaing \\
\hline 1993 & 8 & 9 & 36.38 & 70.87 & 214.50 & 7.0 & 2.00 & Afghanistan $53 \mathrm{~km} \mathrm{~S}$ of Jurm \\
\hline 1997 & 2 & 27 & 29.98 & 68.21 & 33.00 & 7.1 & 2.82 & Pakistan, Harnai \\
\hline 2002 & 3 & 3 & 36.50 & 70.48 & 225.60 & 7.4 & 7.94 & Afghanistan Hindu Kush \\
\hline 2005 & 10 & 8 & 34.54 & 73.59 & 26.00 & 7.6 & 15.85 & Pakistan, Azad Kashmir \\
\hline 2013 & 9 & 24 & 26.95 & 65.50 & 15.00 & 7.7 & 22.39 & Pakistan, Balochistan \\
\hline 2015 & 4 & 25 & 28.23 & 84.73 & 8.22 & 7.8 & 31.62 & Nepal, Gorkha \\
\hline 2015 & 5 & 12 & 27.81 & 86.07 & 15.00 & 7.3 & 5.62 & Nepal, $18 \mathrm{~km} \mathrm{SE}$ of Kodari \\
\hline 2015 & 10 & 26 & 36.52 & 70.37 & 231.00 & 7.5 & 11.22 & $\begin{array}{l}\text { Afghanistan Alaqahdari-ye Kiren Wa } \\
\text { Munjan }\end{array}$ \\
\hline 2015 & 12 & 7 & 38.21 & 72.78 & 22.00 & 7.2 & 3.98 & Tajikstan Murgab \\
\hline
\end{tabular}

conditions in the early twentieth century, would inhibit our intended purpose.

The great earthquake in Assam on 1950 August 15 with magnitude 8.6 is the largest earthquake in the region and is an extremely rare event. This earthquake and its spatial-temporal juxtaposed moderate- strong earthquake groups and aftershocks fluctuate greatly, reflecting the localised distribution of coseismic energy release. To reflect better on the continuing seismic activity, the earthquake catalogue starting 1951 is adopted (we return later to omission of the great Assam 1950 earthquake). Although a 
(a)

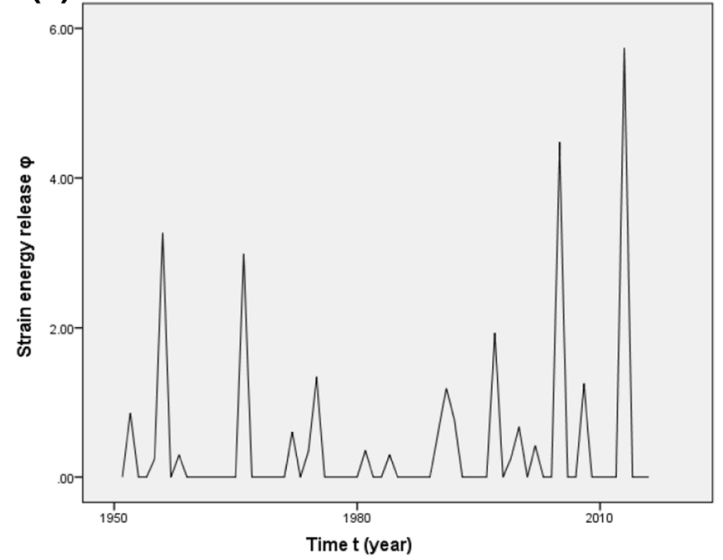

(c)

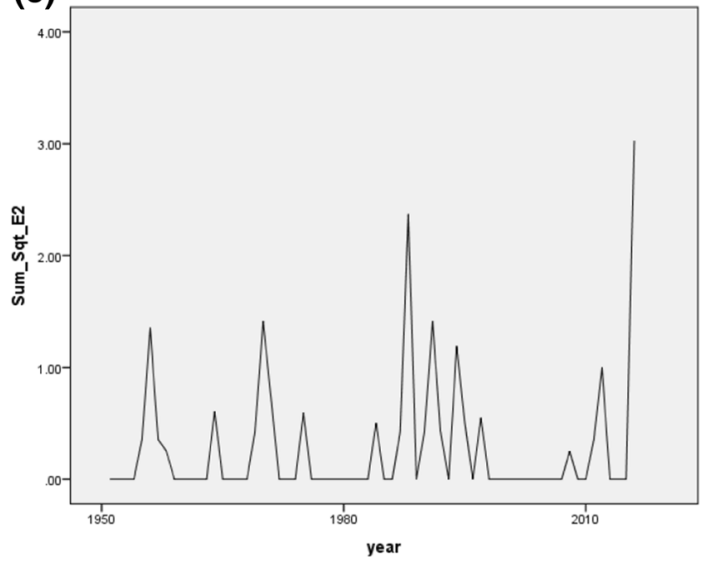

(e)

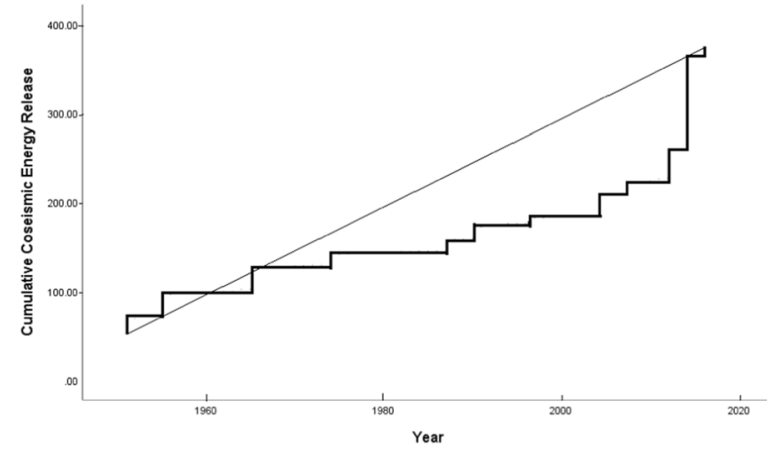

(b)

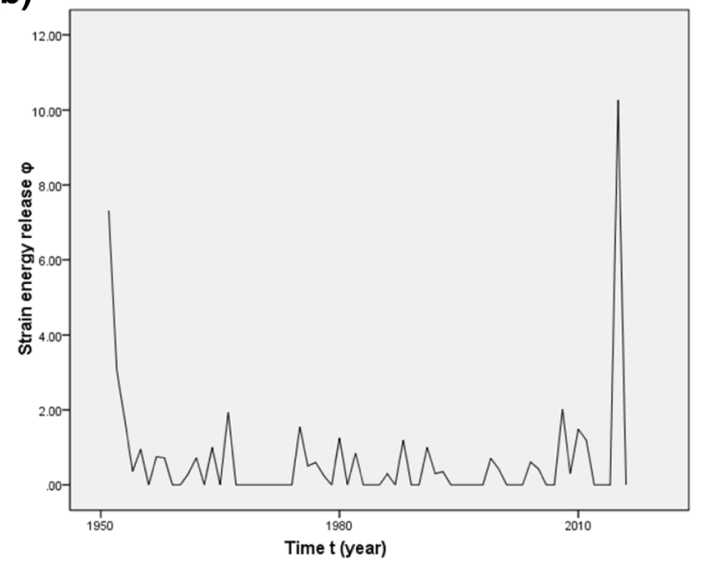

(d)

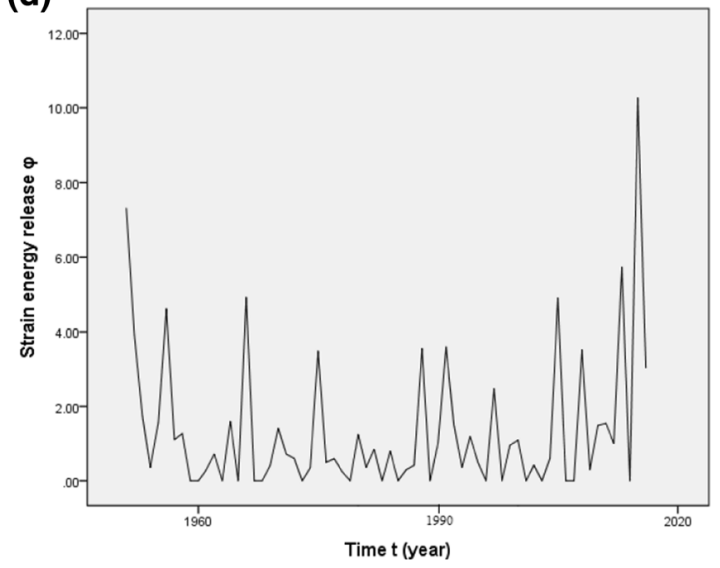

(f)

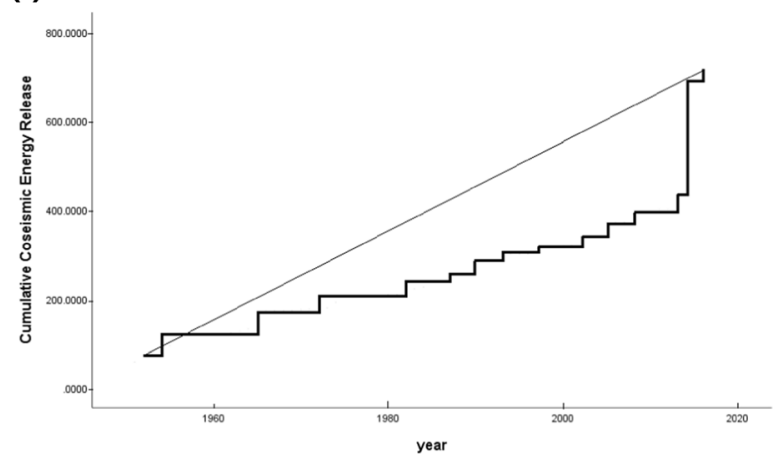

Figure 2

Time sequences for square root coseismic energy release, $E_{i}^{1 / 2}(\mathrm{t})$, in the Himalayan Tectonic Belt. Ordinate is $\varphi(t)=E_{i}^{1 / 2}(\mathrm{t}),\left(E^{1 / 2} 10^{11} \mathrm{~J}^{1 / 2}\right)$, and abscissa is time ( $\mathrm{t}$ year) for: a West zone, b Centre zone, $\mathbf{c}$ East zone and $\mathbf{d}$ West, Centre and East zone combined as the Himalayan Tectonic Belt. Ordinate is cumulative coseismic energy release $\Sigma E_{i}(\mathrm{t}),\left(E 10^{22} \mathrm{~J}\right)$, and abscissa is time (t year) for: e Himalayan Tectonic Belt and f Himalayan Tectonic Belt Plus Pamir

greatly improved record of the $\mathrm{M} \geq 5.0$ earthquakes has been kept during this period, given better instrumentation and monitoring networks, considering the geographical width of the research area, from Burma to Pamir, the quality of seismic monitoring conditions varies in this area. Thus, the 
$M \geq 6.0$ earthquake event threshold was considered, the cumulative earthquake frequency and magnitude of the ensuing catalogue were analysed using the Gutenberg-Richter relation and the catalogue found to be complete and therefore to be a reliable data base for study. Using $M \geq 6.0$ as a magnitude threshold means that the seismic activity of Himalayan tectonic belts is studied with data from larger or strong earthquakes in accord with the tectonic scale of the Himalaya. This also avoids interference and false inferences on seismic activity of this global plate boundary which might arise by selecting a profusion of randomly distributed disturbances of $\mathrm{M}=5$ strength seismic components. Strong earthquakes and seismic hazard in Nepal studied following the Ghorkha earthquake in 2015 May $8(\mathrm{M}=7.8)$ also provided opportunity to improve the earthquake catalogue ( $M \geq 6.0,1951-2016$ ) (Burton et al., 2019).

Ways are needed to represent the earthquake time sequence. It is more convenient for analysis to represent an earthquake time sequence as a cumulative coseismic energy release time sequence $\Sigma E_{i}(\mathrm{t})$, rather than adopt the utilitarian magnitude (Makropoulos \& Burton, 1983). The energy release is also a significant parameter suggested by Benioff (1951), who adopted the square root of the coseismic elastic wave energy, $E_{i}^{1 / 2}(\mathrm{t})$, released by the earthquake to study its change over time. This provides another view of the earthquake sequence; using $E_{i}^{1 / 2}$ released in each earthquake of a sequence we can explore the time variations of seismic activity. Based on the above earthquake catalogue, the corresponding events in the Himalaya or sub-regions are selected and using the year as the unit of time calculate the time series $\varphi(t)$ composed of the square root values $E^{1 / 2}$. Then

$$
\varphi(t)=\sum_{i=1}^{N} E_{i}(t)^{\frac{1}{2}}
$$

where $E_{i}$ is coseismic energy release and $N$ is the number of events in a year. The equation used to calculate $E_{i}$ is:

$$
E_{i}=10^{1.5 M_{i}+11.8}
$$

where $M_{i}$ is the earthquake magnitude of an event (USGS, 2002; Yin et al., 2012).

Now we return to the fundamental properties of the earthquake catalogue. The catalogue consists of
1919 earthquakes with $M \geq 5.0,290$ with $M \geq 6.0$, 41 with $M \geq 7.0$ and three great earthquakes with $M \geq 8.0$. The latter three earthquakes are those dated 1934 January 15 and 1946 September 12, both with $\mathrm{M}=8.0$, and the great Assam earthquake of 1950 August 15 with $\mathrm{M}=8.6$. There are no earthquakes with $\mathrm{M}$ under 6.0 in the catalogue before 1950. Opting for 1951-2016 provides a 66-year duration catalogue with $M \geq 6.0$. It is re-emphasised that the selection of $\mathrm{M}=6.0$ as the low magnitude threshold is of universal significance for the study of global scale, plate boundary, active faults. The smaller and medium-sized earthquakes are random and not necessarily directly tectonically controlled. The stronger earthquakes above this magnitude threshold can convey tectonophysical characteristics, and insights, with greater clarity. Elsewhere, the study on survival of seismogenesis for large earthquakes is an example using an $M=6.0$ foundation (Xu \& Burton, 2014).

But why window the catalogue in time from 1951? Why exclude the great Assam 1950 earthquake? This is done for two reasons. Inspect the cumulative coseismic energy releases in the whole Himalayan Tectonic Belt (West, Central and Eastern zones combined) in Fig. 2e and in the whole Himalayan Tectonic Belt plus Pamir zone in Fig. 2f; these figures include the magnitude $\mathrm{M} \geq 6.0$ and $\mathrm{M} \geq 7.0$ earthquakes of the catalogue. The step of cumulative coseismic energy release $\Sigma E_{i}(\mathrm{t})$ or $\Sigma E_{i}$, from first to last point in the whole Himalaya time sequence $E_{i}(\mathrm{t})$ or $E_{i}$ (Fig. 2e), averaged per annum (which is the gradient of the line in Fig. 2e), is $5.67 \times 10^{22} \mathrm{~J}$ p.a., equivalent to an annual magnitude of $\mathrm{M}_{2}=7.3$ $\left(\mathrm{M}_{2}\right.$ : Makropoulos \& Burton, 1983). The total $\Sigma E_{i}=3.74 \times 10^{24} \mathrm{~J}$ for the 66-year catalogue of the whole Himalaya. Similarly, now including the Pamir with the Himalaya (Fig. 2f), the step of coseismic energy release from first to last point in the whole Himalaya plus Pamir time sequence $\Sigma E_{i}$, averaged per annum, is $10.85 \times 10^{22} \mathrm{~J}$ p.a., equivalent to an annual magnitude $\mathrm{M}_{2}=7.5$. Total $\Sigma E_{i}=7.16 \times$ $10^{24} \mathrm{~J}$ for the 66-year catalogue. Consider that the great Assam 1950 earthquake on its own had a coseismic energy release $E(\mathrm{M}=8.6)=5.01 \times 10^{24}$ J. The great Assam 1950 earthquake on its own released more coseismic energy than the entire Himalaya achieved over 66-years and $70 \%$ of that 
achieved by the Himalaya plus Pamir combined. While it is common practice to consider the great earthquakes of the Himalaya to be the essence of its seismicity, in fact they are the antithesis of the norm of tectonic seismicity, which it is our aim to inspect, seeking evidence of any commonality of properties across the zones.

The second reason to exclude Assam 1950 is more mundane and methodology dictated in relation to capabilities of resolution using Morlet spectra analysis. Inspect the four figures of time sequenced square root coseismic energy release $E_{i}^{1 / 2}(\mathrm{t})$ or $\sum E_{i}^{1 / 2}$ for West, Central, East and whole Himalaya (Fig. 2a-d). Taking the square root of energy $E_{i}^{1 / 2}$ reduces the dynamic range of numbers to be analysed in a Morlet's spectra analysis; never-the-less inclusion of Assam 1950 would dominate the dynamic range by an order of magnitude, for just one event in time, and render resolution of any periodicity in the normal, regular seismicity of the Himalaya overshadowed and impossible to resolve satisfactorily. The situation is similar for the Morlet's spectral analysis of the Himalaya plus Pamir.

There is a further issue that might be of concern. Does removing the great Assam earthquake of 1950 emasculate the seismic potential of the Himalaya and Pamir seismicity; as resides in and is expressed by the 66-year earthquake catalogue used to identify evidence of commonality or harmony in the normal seismicity across the Himalaya and Pamir zones? The anomalous steps or excursions in the last two years of the $\Sigma E_{i}(\mathrm{t})$ staircases in Fig. 2e, f are contributed to by eleven earthquakes in the range $M=6.0-6.9$ and, more importantly, four in the range $\mathrm{M}=7.0-7.9$ in 2015 , hence the large step towards the end of the stair case. The magnitude $\mathrm{M}_{2}$ equivalent to the annual average energy release is $\mathrm{M}_{2}=7.3$ for the Himalaya (Fig. 2e) and is $\mathrm{M}_{2}=7.5$ for the Himalaya plus Pamir (Fig. 2f). An upper bound magnitude to regional earthquake occurrence has been defined, both analytically and graphically, by examination of the high-seismicity in the circum-Pacific region $\left(\mathrm{M}_{3}\right.$ : Makropoulos \& Burton, 1983). The upper bound magnitude, $\mathrm{M}_{3}$, is found to relate to $\mathrm{M}_{2}$ through a simple empirical relationship: $\mathrm{M}_{3}-\mathrm{M}_{2}=1$. Thus, the $E_{i}(\mathrm{t})$ of the relatively short 66-year earthquake catalogue employed herein, through the cumulative
$\Sigma E_{i}(\mathrm{t})$ and $\mathrm{M}_{2}$ in the Himalaya and Himalaya plus Pamir, point to upper bound magnitudes $\mathrm{M}_{3}$ of $\mathrm{M}_{3}=8.3$ and $\mathrm{M}_{3}=8.5$ respectively. The great Assam earthquake is this upper bound with magnitude $\mathrm{M}_{3}=8.6 \mathrm{M}_{\mathrm{w}}$ with a commensurate uncertainty. Removing Assam 1950 from the earthquake time sequence $E_{i}(\mathrm{t})$ of the Himalaya plus Pamir seismicity does not emasculate the implicit seismic potential of the earthquake catalogue adopted. The earthquake time sequence $E_{i}(\mathrm{t})$ adopted to examine normal seismicity has the memory to accommodate and point to the potential upper bound to Himalaya plus Pamir seismicity.

\section{Harmonic Provenance Fourier, Schuster and Morlet: Morlet Wavelets}

Since Joseph Fourier (1768-1830, see Bracewell, 2000) first studied heat flow in the Earth using his contentious idea that an arbitrary function could be represented by a single analytic function the provenance of harmonic analysis to analyse a time series has become established.

The representation of a time series as a sequence of numbers can be analysed to identify dominant harmonics or periodicities, trends and even used to predict futures using history; aims which have had long development. Fourier series uses summed cosinusoids to create an equivalent representation to the time sequence of numbers but in a second domain (frequency as opposed to time); here the time sequence becomes a spectrum of harmonic components (in proportion to, or weighted by, the modulus of the sinusoidal coefficients, with phase differences between the harmonics) - hence we have the Fourier series and transform. We also thus arrive at the generation of Fourier transform pairs, when a function which can be represented analytically in time has Fourier transform which is an analytical function in frequency. Well known examples are: Gaussian function transforming to another Gaussian, sinc function transforming to unit rectangle function and $s i n c^{2}$ function transforming to triangle function; all useful when visualizing deconvolution and filter operations and Bracewell (1965) provided a pictorial dictionary of such pairs "for inspiration". An 
analytical function or time sequence is required to extend from $-\infty$ to $+\infty$ which in practice for physical time sequence considerations leads to discretised time sequences, sampling intervals and bandwidth considerations.

Achieving Fourier transform or Fourier series representation of a time sequence of numbers was arithmetically tedious; see Schuster's (1897) analysis related to earthquake occurrences linked to possible Earth-Moon-Sun interactions to recognise such tedium and arithmetic labour, until the Cooley-Tukey (1965) algorithm facilitated rapid machine calculation (this algorithm born of the need to analyse the glut of seismograms required for nuclear explosion test's monitoring). The advent of the Cooley-Tukey algorithm allowed the rapid computation and transition between the domains of time and frequency needed to achieve discretised Fourier pairs and coefficients. With the knowledge that an entirely real physical time signal could be represented as a complex variable ushered in the ability to obtain the spectral content of the "wiggles", as later referred to by Grossman and Morlet (1984), to carry out deconvolution, and to measure physical properties of materials in the Earth. As one example from many, with these tools, a seismogram could be analysed with a suitable set of band-pass filters in the frequency domain as one step, followed by reverse Fourier back to time for each filter in the set to identify and localise arrival times when energy arrived at each specific filter central frequency-this being pinpointed as the maximum of the time domain analytic signal-hence obtaining group velocities for a wave propagating in space (e.g. Burton \& Blamey, 1972, is one of several). These methods, alongside the ability to compute spectral amplitudes, were next used to measure the anelastic attenuation factor or quality factor, Q, within the Earth (Burton, 1974). There are many similar examples which embrace the ability to analyse wave and wave fronts advancing through the Earth from a source, and the physical properties encountered en route. However, the earthquake sources themselves and the time sequence constructed from a regional history of earthquakes describe a point process (of earthquake occurrence dates in time) rather than the passage in time of a wave front at a point in space. The question arises, does the time sequence of earthquake history contain harmonics, periodicities, dictated by some underlying process, which might be known or not known? Schuster, long ago in 1897, addressed this issue by laborious arithmetical calculation of sinusoidal coefficients of Fourier series representation of regional earthquake histories, inspecting for periodicities which might, or might not, be linked to lunar influence, and, vitally, introduced probability calculation to test if amplitude of any periodicity was significantly different to that expected from a purely random process of earthquake occurrence in time. This approach has been exploited for over a century. A modified Schuster approach has recently been applied by Ader and Avouac (2013) to Nepalese seismicity which spans a significant extent of the Himalayas that is of interest to us. They discern a $40 \%$ increase of seismicity (intermediate magnitudes) in winter but no periodicities that might be linked to tidal variation. However, strategies have existed for some time to move away from such approaches, and away from pure sinusoidal Fourier series, to those advocated by Grossman and Morlet (1984).

Whereas summed sinusoids are intuitive as representation of harmonics in a propagating wave (and frequency or harmonic content can be manipulated to be inspected in the time domain), they are not intuitive as representation of periodicity in time sequenced earthquake history. Alternative windowing techniques can simultaneously evaluate the spectral periodic content of a point process in time and its variability through time; the methods of Grossman and Morlet (1984) have advantages in that they achieve this two-pronged target. What follows is guided by the practical advice for implementation given by Torrence and Campo (1998).

The Morlet wavelet is one which contains a complex exponential carrier multiplied by a Gaussian window. It was suggested by Jean Morlet in seismological application, who cooperated with Grossman to give a system and base for this wavelet transform (Grossman \& Morlet, 1984). So, the Morlet wavelet function is defined as

$$
\psi(t)=\pi^{-1 / 4} e^{i \omega_{0} t} e^{-t^{2} / 2}
$$

where $\omega_{0}$ is the nondimensional frequency and $t$ is time (Torrence and Campo, 1998). A wavelet 
(ai)

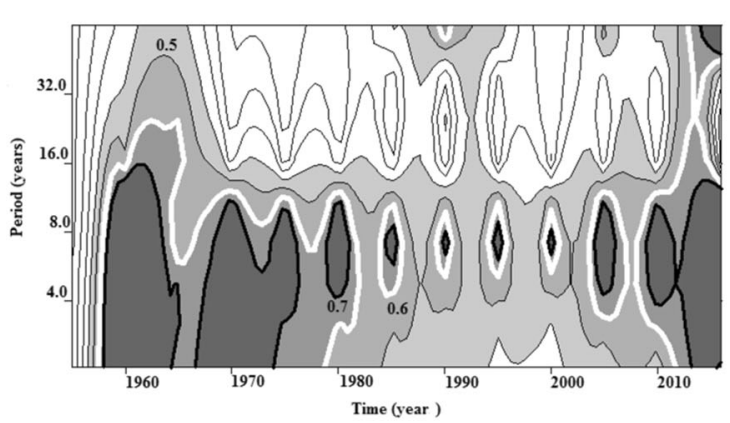

(bi)

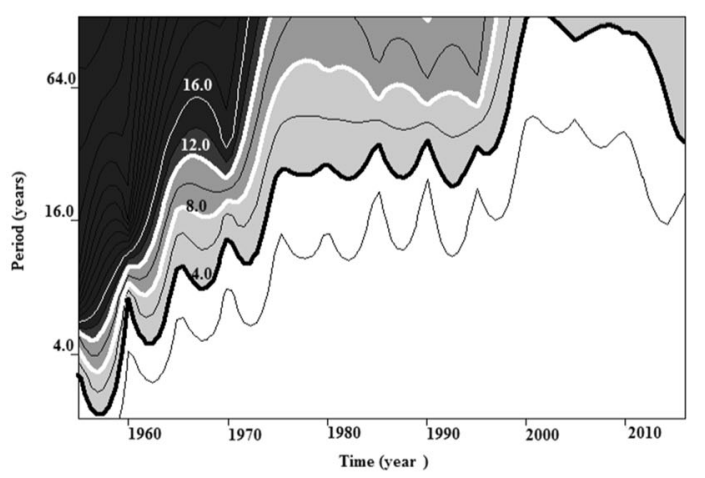

(ci)

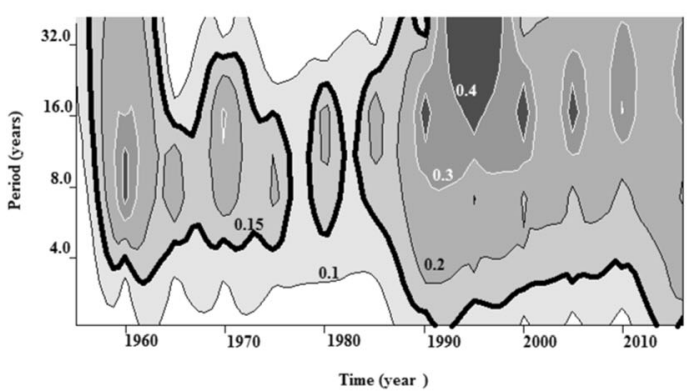

(di)

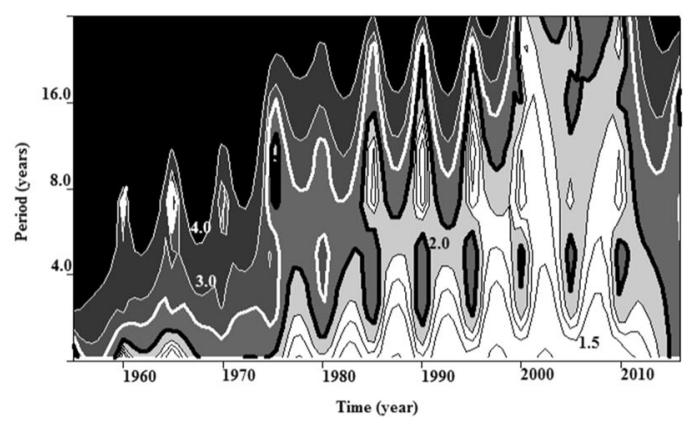

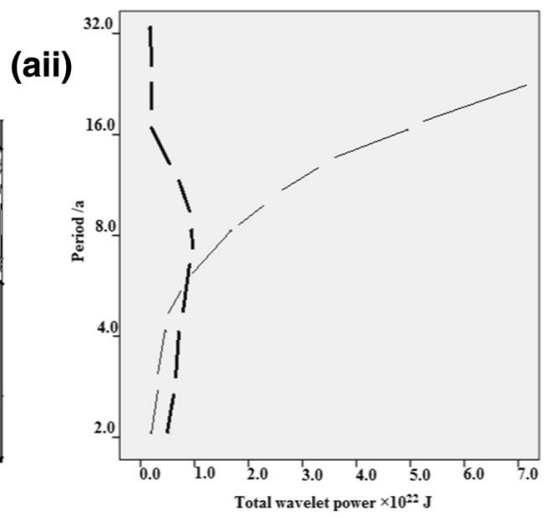

(bii)

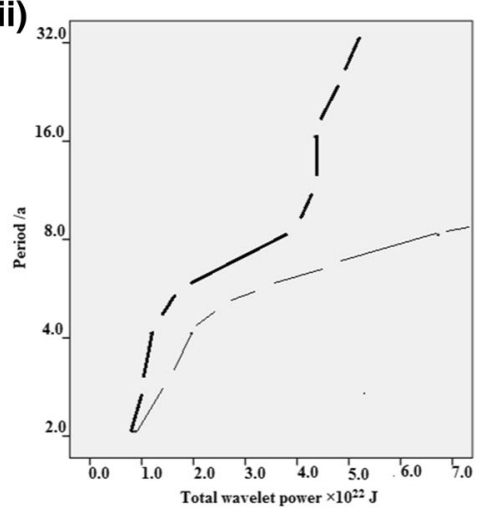

(cii)

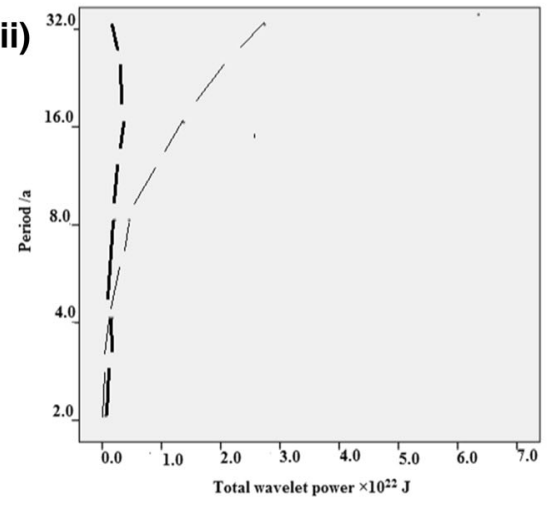

(dii)

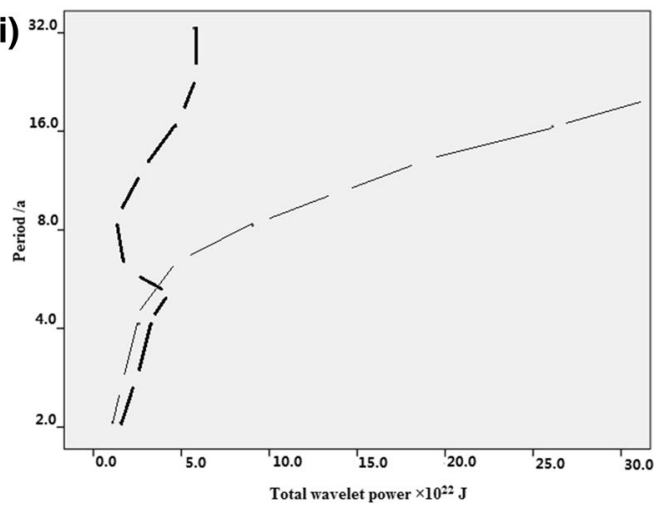


Figure 3

Morlet wavelet analysis for the Himalayan Tectonic Belt and significance testing. a-c Are West, Centre and East zones, combined in $\mathbf{d}$ as the Himalayan Tectonic Belt. i indicates: Morlet wavelet spectrum of $E_{i}^{1 / 2}(\mathrm{t})$ energy released $\left(10^{11} \mathrm{~J}^{1 / 2}\right)$. Key energy spectrum amplitudes are labelled. ii indicates: significant periodicities of $E_{i}^{1 / 2}(\mathrm{t})$ energy released. The thick dashed line represents the total wavelet energy. The thin dashed line is the $95 \%$ confidence level to be exceeded to indicate significance. Abscissa is the total wavelet power $\left(10^{22} \mathrm{~J}\right)$ and ordinate is the periodicity

transform could be built using alternative windows; the one in (3) being built using a Gaussian is the Morlet wavelet. There is a condition to be a wavelet which is that the mean of the window is zero. For the Morlet Gaussian window to meet the admissibility condition then $\omega_{0}=6$ and is localised in both time and frequency domains (Farge, 1992). This Morlet wavelet can then be used to examine nonstationary power over a range of frequencies with a Gaussian assisting localisation in both domains. (The Gaussian function Fourier pair is also a Gaussian function as graphically illustrated by Bracewell, 1965, 2000.) A regional earthquake history is a discrete sequence in time. The discrete wavelet transform formula is

$$
W_{f}(a, b)=|a|^{-\frac{1}{2}} \sum_{i=1}^{N} f(i \delta t) \psi *\left(\frac{i \delta t-b}{a}\right)
$$

and $\psi^{*}$ indicates complex conjugate. $a$ is scale factor which is related to period $T$ and frequency $\omega . b$ generates translation related to time location. $i$ is the data sequence time position label. $f(i \delta t)$ is the digitised equivalent to the variable time series $f(t)$. The $\delta t$ is the variable sequence time interval. $W_{f}(a, b)$ is a wavelet coefficient. For many wavelets the scale factor $a$ is dissimilar to values obtained using Fourier transform for period $T$ and frequency $\omega$. For the Morlet wavelet with $\omega_{0}=6$, and with $4 \pi a /\left[\omega_{0}+\left(2+\omega_{0}^{2}\right)^{0.5}\right]$ for $T$ gives a value of $1.033 a$; indicating that for the Morlet wavelet, the wavelet scale is almost equal to the Fourier period, differing by circa $3 \%$ (Torrence and Campo, 1998).

The wavelet power spectrum is

$$
E_{a, b}=\left|w_{f}(a, b)\right|^{2}
$$

and the overall wavelet power spectrum that characterizes the corresponding energy density at different scales is given by

$$
E_{a}=\frac{1}{N} \sum_{b=1}^{N}\left|w_{f}(a, b)\right|^{2}
$$

The search for significant periodicities in earthquake histories by inspecting Fourier sinusoidal coefficients becomes rigorous when specific coefficients are demonstrated to be significantly different to those arising by chance in a random process (Ader and Avouac, 2013; CalTech, 2012; Schuster, 1897). Similarly, the statistical test for the Morlet spectrum is important. The Morlet power spectrum can be compared with a reference noise spectrum. Red and white noise are usually considered standard for such tests, typically red noise is used to determine if a Morlet wavelet power spectrum contains harmonics that are significantly different to those expected due to noise alone (Torrence and Campo, 1998; Yin et al., 2012). If $p_{a}$ is the spectrum for the red noise, then it is given by

$$
p_{a}=\frac{1-\alpha^{2}}{1+\alpha^{2}-2 \alpha \cos \left(\frac{2 \pi \delta t}{1.033 \alpha}\right)}
$$

where $\alpha$ is the assumed lag -1 autocorrelation and $\delta t$ is the data sequence time interval. The overall wavelet power spectrum characterizes the corresponding energy density at different scales $a$. The theoretical red power spectrum is given by

$$
p=\frac{\sigma^{2} p_{a} \chi_{v}^{2}}{v}
$$

where $\chi_{v}^{2}$ is the value for distribution $\chi^{2}$ with $v$ degrees of freedom at the significance level 0.05 and $\sigma^{2}$ is the variance of the original data sequence. Any periodicity in the overall wavelet power spectrum is significant when $E_{a}>p$. The significance testing associated with the Morlet spectra that follow use graphs to display both $E_{a}$ and $p$ for all periodicities inspected.

\section{Himalayan Tectonic Belt: Morlets and Periodicity}

Data considerations dependent on the 66-year earthquake catalogue of $M \geq 6.0$ earthquakes, constraints to facilitate the targets of this research, and the ability to use the Morlet's wavelet methodology, were explained fully in Sect. 2. The Morlet wavelet 
and the Morlet wavelets analysis methodology, and its provenance, have been discussed in Sect. 3. The procedure of the next two Sections will be to consider in this Sect. 4 the three zones-West, Central, East of the Himalaya and then the three combined into the Himalayan Tectonic Belt; and then Sect. 5 will consider the Pamir zone and then the Pamir zone combined with the Himalayan Tectonic Belt, or Himalayan Tectonic Belt Plus.

The Morlet wavelet variation's characteristics and their significance for the sub-zones and whole-zone of the Himalayan Tectonic Belt zones will now be analysed. The four sequences of coseismic energy release in time, $E_{i}^{1 / 2}(\mathrm{t})$, for which Morlet wavelet spectra will be sought are illustrated in Fig. 2a-d.

As can be seen from Fig. 3ai, characteristics for the Morlet wavelet spectrum of the time sequence $E_{i}^{1 / 2}(\mathrm{t})$ of energy release for the West zone indicate on eye-ball inspection that there is a periodicity of 8 9 years of activity. However, the significance testing for periodicities of $E_{i}^{1 / 2}(\mathrm{t})$ illustrated in Fig. 3aii shows that this periodicity does not pass the $95 \%$ confidence test when compared to red noise (Eq. 7). Figure 3ai does show that the ramp-like right edge of the test failing 8-9 years periodicity appears at the edge of the energy spectrum around the 5-year periodicity, exceeding the test level (inspect intersection of heavy and light dashed lines in Fig. 3aii). This periodicity reflects the convergent movement of the Indian plate obliquely relative to the Eurasian plate and is of some reference value. However, this reference periodicity as a distinct characteristic is blurred or perhaps becomes indistinct due to the complexity of the Sulaiman Range and its folding and thrusting tectonic activity caused by the plate's convergent movement.

By contrast inspection of the Morlet analysis in Fig. 3bi does not indicate any periodic activity feature in the Centre zone. This is rigorously confirmed in Fig. 3bii which also does not indicate any periodicity characteristics that even approach passing the significance test level. This Centre zone is essentially the largest, most basic and important sub-zone of the Himalayan seismicity belt. From the beginning of the twentieth century to the end of 2016, a total of 105 earthquakes with $\mathrm{M} \geq 6.0$ occurred in this zone. Among these were 12 major earthquakes with $\mathrm{M}$ $\geq 7.0$, including the great earthquake that took place on 1934 January 15 with magnitude 8.0 in the Bihar region. The Centre zone includes the largest earthquake in the Himalayan Tectonic Belt which took place on 1950 August 15 with magnitude 8.6 in the Assam area of the zone. The earthquake sequence of strong earthquakes $M \geq 6.0$ when represented by $E_{i}^{1 / 2}(\mathrm{t})$ does not indicate any significant periodicity in this large zone. This may be related to the very rarity of the strongest earthquakes and available data. The strong earthquakes are unevenly distributed in time and space and very large earthquake energy has been released in a few temporal epochs, concentrated in a few locations. Such localisations of energy are neverthe-less associated with convergence motion of the plates in this, the large Centre zone. Yet this same motion has also produced a complexity of active seismotectonics for the extraordinary earthquake, for example: Assam 1950 was accompanied by rightlateral strike-slip fault movement, whereas Bihar 1934 was accompanied by reverse-slip fault movement.

In contrast the Morlet analysis in Fig. 3ci indicates a periodicity in the East zone of circa 17 years. This periodicity is well below the $95 \%$ confidence test level in Fig. 3cii. The whole curve in Fig. 3cii is almost flat and periodicity around 3-4 years is obscure and hardly emerges to exceed the $95 \%$ confidence test level against red noise (again inspect the heavy and light dashed lines in Fig. 3cii), but it is a peak-like edge, suggesting its significance is limited. This reference-periodicity feature can be taken to reflect subduction of the Indian plate dipping eastward. At the same time, due to the complexities of occurrence of a combination of strike-slip and reverse fault motion within the Indian-Burmese tectonic arcs, the periodicity characteristics are not outstanding.

The Himalayan Tectonic Belt consisting of West, Centre and East zones is now taken in entirety. Inspection of the energy release characteristics resulting from the Morlet analysis in Fig. 3di indicates that there is a periodicity of $5 \pm 1$ year. The significant periodic spectrum of $E_{i}^{1 / 2}(\mathrm{t})$ in Fig. 3dii shows that this periodicity has a sharp peak which clearly passes the $95 \%$ confidence test against the red noise level. The time sequence for $E_{i}^{1 / 2}(\mathrm{t})$ released in the Himalayan Tectonic Belt illustrated in Fig. $2 \mathrm{~d}$ 
(a)

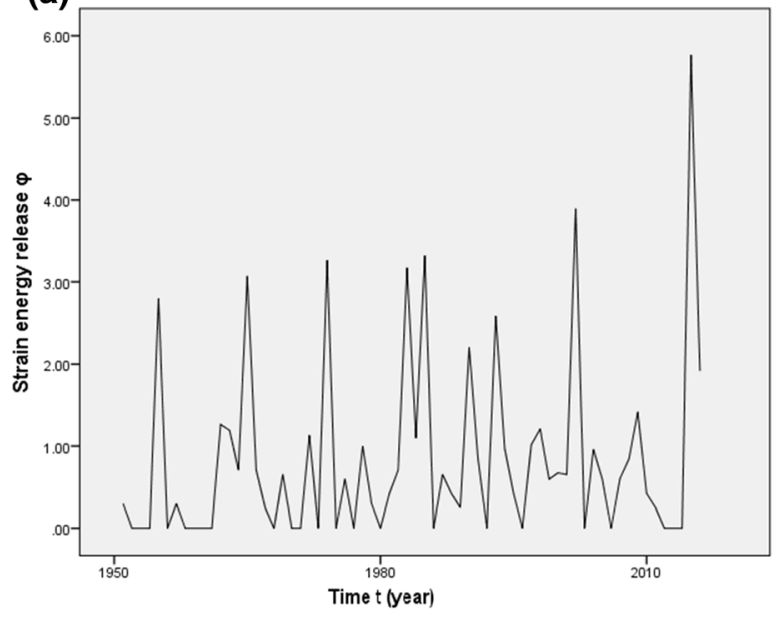

(b)

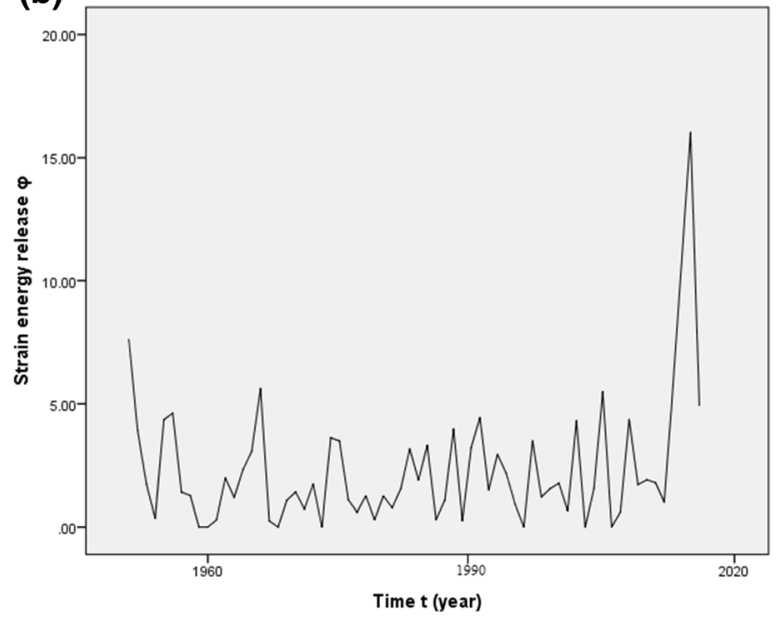

Figure 4

Time sequences for $E_{i}^{1 / 2}(\mathrm{t})$ energy released in the Himalayan Tectonic Belt Plus. Ordinate is $\varphi(t)=E_{i}^{1 / 2}(\mathrm{t}),\left(E^{1 / 2} 10^{11} \mathrm{~J}^{1 / 2}\right)$, and abscissa is time (t year). a Pamir-Hindu Kush Tectonic zone, b Pamir-Hindu Kush zone and Himalayan Tectonic Belt combined as the Himalayan Tectonic Belt Plus

roughly confirms the up-and-down excursions of the above periodicities as periodic activities.

In summary, it can be stated that for the Himalayan Tectonic Belt, the Morlet wavelet spectrum shows that the Centre zone does not have a periodic feature with $95 \%$ statistical significance. The Centre zone is the core of the convergence movement of the Indian and Eurasian plates. The temporal and spatial distribution of seismic activity is non-periodic, or it has an extremely uneven spatial and temporal distribution. This may cause a large earthquake energy release to be highly concentrated in individual periods and regions. In other words, huge earthquakes can occur in this area. This tectonic characteristic of the zone revealed here might be a cause for the strongest earthquake in history: 1950 Assam M8.5 event occurred in this zone.

The Eastern and Western zones of the Himalayan Tectonic Belt are respectively turned into the Pakistan and the Burma structural arcs and deep into the inner depressions of the Eurasian plate. In other words, the West and the East zones are where the two sides of the convergence motion of the plates in the Centre zone correspond to the complex motions of the confluent structural adjustment. Both the East and West zones have a periodicity of circa $5( \pm 1)$ years reference seismic activity, confirmed with $95 \%$ statistical test significance, but emerging with obscure ramp-like shape at the significance level. Different to the foregoing is absence of any detectable seismic periodicity in the large Centre zone. Combining West, Centre and East zones to form an overall Himalayan Tectonic Belt discerns an overriding general feature of periodicity of 5 years that easily passes the $95 \%$ statistical significance test at a sharp peak.

In music, harmony means an acoustic combination composed of two or more different individual sounds that sound at the same time as if in consonance with a certain rule. Here, the Centre zone, the West zone, and the East zone each have their own characteristics of different periods (or non-periods) of seismicity. This is equivalent to three different individual sounds in the above musical analogy. Thus, the overall Himalayan Seismic Activity Belt, and plate convergence belts, formed by these three zones, has the characteristic of periodicity of earthquake activity and is equivalent to the harmony of sound. Seismic Harmony reflects the unity and harmony of the tectonic stress of the plate convergence movement in the Himalayan Active Belt. There is a commonality of property in seismicities for the Himalayan Tectonic Belt as a whole. 

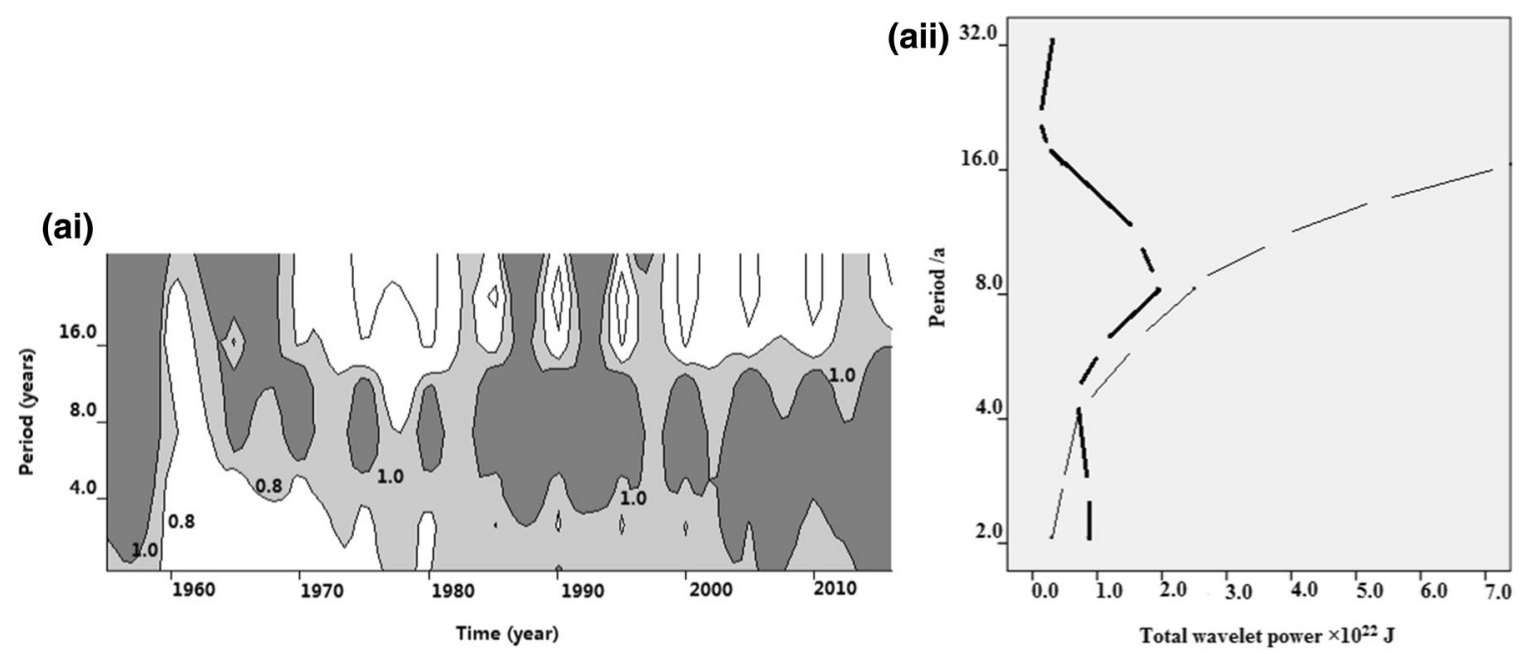

(bi)
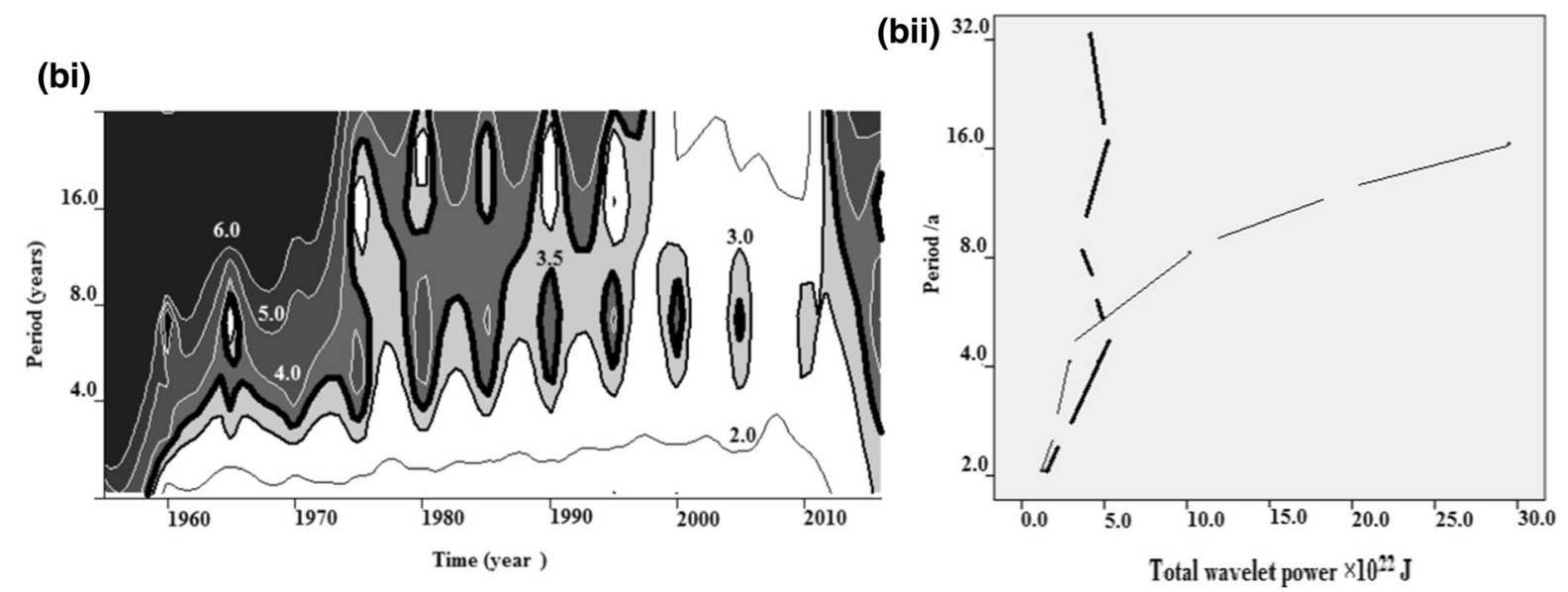

Figure 5

Morlet wavelet analysis for the Himalayan Tectonic Belt Plus. a Pamir-Hindu Kush Tectonic zone, b Himalayan Tectonic Belt Plus. i indicates Morlet wavelet spectrum and ii indicates the corresponding significance testing, both as described in Fig. 3

\section{Himalayan Tectonic Belt Plus: Morlets and Periodicity}

The Himalayan Tectonic Belt at its west end forms west-end tectonic knots in Nanga Parbat, and then turns into the interior of the Eurasian plate in depth. The influence of the western structures reaches directly into the Hindu Kush in the Pamir zone (see Fig. 1) (Den et al., 2014; USGS, 2014). Such interaction leads to this attempt to establish existence of periodicities and explore seismic harmony for the Himalayan Tectonic Belt plus the Pamir zone i.e. Himalayan Tectonic Belt Plus. Both time series of
$E_{i}^{1 / 2}(\mathrm{t})$ released for which Morlet wavelet analysis is required are illustrated in Fig. 4.

The Morlet analysis in Fig. 5ai suggests a periodicity in the Pamir zone at 8-9 years, but this periodicity does not pass the $95 \%$ confidence test (Fig. 5aii). The complexity of seismic activity in the Pamirs is contributed to by both deep seismic activity of the lithosphere subduction movement and shallow seismic activity that reflects the main Pamir thrust; these together may account for the apparent periodicity. Once again reference periodicities below 4-5 years emerge, ramp-like at the $95 \%$ significance test (Fig. 4aii). 
Inspection of Fig. 5bi suggests a period of about $5 \pm 1$ years of activity for $E_{i}^{1 / 2}(\mathrm{t})$ released in the Himalayan Tectonic Belt Plus. Significance testing of the spectrum of periodicities in Fig. 5bii identifies a peak of periodicities extending from 8 years which straddles the significance test level and leads into a peak of periodicity at $5 \pm 1$ year which is significant well above the $95 \%$ confidence level. Such periodicity around 5 years is compatible with the up-anddown excursions of apparent periodic activities in Fig. 4b.

Finally, comparing the heavy-dashed curves representing the total Morlet wavelet power spectrum for the Himalayan Tectonic Belt Plus with the Himalayan Tectonic Belt (Figs. 3dii, 5bii) reveals a similarity, i.e. both have two peaks in the power spectrum-but in each case only the $5 \pm 1$ year periodicity passes the $95 \%$ significance test level. The stand-alone Pamir zone contains a significance testfailing peak and a $5 \pm 1$ year periodicity ramp-like feature emerging near the $95 \%$ significance level. We are again observing an example of seismic harmony as noted previously in Sect. 4. We conclude that it is a reasonable step to include the Pamir zone into the Himalayan Tectonic Belt as one large tectonic family. This large family may thus have a unified structural activity stress field dictated by the plate convergence belt-again there is a commonality of property in seismicities.

\section{Discussion and Conclusions}

Our modelling of seismicity, earthquake sequence, in the Himalayas is founded on wavelet analysis. Wavelet analysis is an evolution of Fourier analysis with its long provenance. The essential difference between Fourier and Wavelets for our purpose is akin to the uncertainty principle: with Fourier exact time or frequency can be identified, not both simultaneously; with Wavelets, both time and frequency can be identified, but neither exactly. There are many forms of wavelet analysis determined by the functional multiplier in Eq. (3); when this is Gaussian then we have Morlet wavelet analysis with the advantage that a Gaussian function transforms into a Gaussian, and the scaling during transform replicates customary time units after transform (which is not the case with many wavelets). Therefore, the method provides opportunity to discern when specific periodicities are dominant and display relative energies of periodicities. Significance testing of periodicities before they can be considered as characteristic of an earthquake sequence is vital and an issue emerges which is raised below. First, we enumerate the significant periodicities identified and comment on commensurate seismic harmony across the Himalaya.

The Centre zone for the Himalayan Tectonic Belt, that is, the structural core zone for the Belt, does not show any wavelet periodicity characteristics that can pass the 95\% significance test. This suggests a nonperiodic, non-uniform spatial-temporal distribution of earthquake movement between the Indian plate and the Eurasian plate. Current earthquake data availability prohibits Morlet analysis for long periodicities that might give detailed insights into the role of the rare great earthquakes which are scattered through Himalayan pre-instrumental history. In the East zone, the Himalayan Tectonic Belt extends eastward and turns to the Burmese tectonic arc while in the West zone, the Belt extends westward and turns towards Pakistan. Then, both structural knots continue northward into the interior of the Eurasian plate. For these two zones the character of the Morlets spectrum differs to the Centre zone; a reference seismic activity periodicity of 4-5 years is evident and just statistically significant: for the Western zone periodicities emerge as significant as a ramp-like adjoint; Eastern zone periodicities occur as an emergent, low peak. This is concurrent with the adjustment of the tectonic movement of the east- and west-end regions of the Himalayan Tectonic Belt relative to its central core. There is a degree of regularity for the East and West zones.

East, Centre and West zones each have different characteristics of wavelet periodicity (or non-periodicity). Together these three zones form the Himalayan Tectonic Belt. This has a periodicity of about 5 years in the earthquake sequence that is significant at the $95 \%$ level and is apparent as a sharp peak in the significance testing. This is seismic harmony, comparable to musical harmony, and 
seismicity in the belt responding to an overarching tectonic stress due to plate convergence.

We also find that the Himalayan Tectonic Belt and the Pamir-Hindu Kush Tectonic Zone are also collaborating as a new large family, the Himalayan Tectonic Belt Plus. Significant periodicities, at or below 5-year in the Morlets spectrum of the PamirHindu Kush zone by itself, and when combined with the Himalayan Tectonic Belt as the Himalayan Tectonic Belt Plus (clear peak of 95\% significance), are discerned. This new combination or whole shares a commonality of property in seismicity-seismic harmony. The Pamir-Hindu Kush Tectonic Zone was created by the extension of the west-end of the Himalayan Tectonic Belt to Pakistan and the intrusion further northward into the Eurasian plate. The seismicity of the Pamir-Hindu Kush Tectonic Zone is complex, composed of deep lithospheric subduction earthquakes and the shallow seismic earthquakes of the Pamir Thrust. This combination of the two, the belt and the zone, extends the suggestion of an overall harmonious response to an overarching active stress field.

As a footnote, we observe peaks of periodicities that fail the significance testing which leave an intriguing dilemma. Graphical significance testing Figures accompanying the Morlet wavelet spectrum analyses of the Himalayan Tectonic Belt and of the Himalayan Tectonic Belt Plus, have twin-peaks of similar shape, each peak being constructed from Morlet wavelet energy values spanning a range of periodicities. These peaks at longer periodicities fail significance testing (there are traces of the same dilemma in East and in Pamir-Hindu Kush Tectonic zones). The dilemma is, does the similarity of twinpeaked curve shape for Himalayan Tectonic Belt and Himalayan Tectonic Belt Plus suggest an insignificant coincidence, or does it suggest corroborative evidence for their existence to be studied further or accepted? There is opportunity for study beyond the scope of this paper which would be helpful: on obtaining and utilising lengthier earthquake sequences, on significance testing and on partitioning earthquake sequences.

In addition, although the seismic samples used in this paper meet the relevant requirements of statistical analysis both in terms of quantity and monitoring data integrity, there is a question: could the number of analysed samples be expanded? A larger sample can more objectively reflect the geophysical conclusions obtained by statistics. However, this way is not in line with the available historical records of local earthquakes in the Himalayan area and the actual monitoring of contemporary seismic instrument.

According to our survey by the Earthquake Engineering Field Survey Team of the Nepal Structural Engineers Society (London) funded by the Engineering and Physical Sciences Research Council (approval number EP/101778X/1), there is no historical earthquake record of magnitude less than 6 before 1950 in this tectonic area. Moreover, judging from the huge geographical scope of the Himalayas and Pamir active tectonic belts, the integrity of historical large earthquake records cannot be proved. This completeness is a necessary condition for the data to be used as the basis of our mathematical analysis.

In this paper, we elaborated in detail to reflect the commonality and objectivity of seismic activity throughout the entire active tectonic belt, and to make the Morlet spectral analysis clear. Our catalogue selected items from 1951 with magnitude 6 or above and lasted for 66 years. The information is complete and high-quality, suitable for high-quality mathematical statistical analysis. It is worth noting here that $4 \mathrm{M}$ or $5 \mathrm{M}$ records in the early 1950 s and early 1960s are not guaranteed to be complete. In the mid1960 s or 1970 s, with the rapid development of modern seismic instrument monitoring technology, many earthquake catalogues of $4 \mathrm{M}, 5 \mathrm{M}$ or below were recorded, greatly improving the number and integrity of the earthquake catalogue database. If the basic data of our research is expanded to include earthquakes of magnitude 5 or 4 or less, then the data may be complete since the mid-1960s, but if it is to start from 1951, data integrity will be a problem. Furthermore, from the point of view of tectonics, it is the best choice for the research on the tectonic boundaries of the Himalayas, which is a global scale, to select strong earthquakes and large earthquakes (Xu \& Burton, 2014). The $4 \mathrm{M}$ or $5 \mathrm{M}$ and other small earthquakes have complex causes and strong randomness. They are not necessarily the cause of active tectonics but may also be caused by 
complicated matters such as weather, landform changes, and human activities and so on. Therefore, it cannot accurately and clearly reflect the geophysical laws and characteristics of this huge-scale activity.

Our research has achieved results under the current conditions that humans have all the seismic data and contemporary seismic monitoring technology. We believe that with the passage of time and the advancement of modern seismic instruments, the seismic record network will be further developed. Our analysis results will be further tested, supplemented, and improved by future seismologists.

\section{Acknowledgements}

YX is pleased to thank David Ball and Ninan Xu for their helpful suggestions and comments. We would also like to thank the Engineering and Physical Sciences Research Council, Grant Number EP/ I01778X/1 for providing funding for PWB to join the Earthquake Engineering Field Investigation Team of the Institution of Structural Engineers (London) in Nepal. This provided opportunity to develop an earthquake catalogue, based on USGS available data, and study seismic hazard in Nepal.

Open Access This article is licensed under a Creative Commons Attribution 4.0 International License, which permits use, sharing, adaptation, distribution and reproduction in any medium or format, as long as you give appropriate credit to the original author(s) and the source, provide a link to the Creative Commons licence, and indicate if changes were made. The images or other third party material in this article are included in the article's Creative Commons licence, unless indicated otherwise in a credit line to the material. If material is not included in the article's Creative Commons licence and your intended use is not permitted by statutory regulation or exceeds the permitted use, you will need to obtain permission directly from the copyright holder. To view a copy of this licence, visit http://creativecommons.org/licenses/by/4. $0 /$.

Publisher's Note Springer Nature remains neutral with regard to jurisdictional claims in published maps and institutional affiliations.

\section{REFERENCES}

Benioff, H. (1951). Crustal strain characteristics derived from earthquake sequences. Transactions of the American Geophysical Union, 32(4), 508-514.

Bollinger, L., Perrier, F., Avouac, J.-P., Sapkota, S., Gautam, U., \& Tiwari, D. R. (2007). Seasonal modulation of seismicity in the Himalaya of Nepal. Geophysical Research Letters, 34, L08304. https://doi.org/10.1029/2006GL029192

Bracewell, R. (1965). The Fourier transform and its applications. McGraw-Hill.

Bracewell, R. N. (2000). The Fourier transform and its applications (3rd ed.). McGraw-Hill.

Bragato, P. L. (2017). Periodicity of strong seismicity in Italy: Schuster spectrum analysis extended to the destructive earthquakes of 2016. Pure and Applied Geophysics., 174, 3725-3735.

Burton, P.W. \& Blamey, C. (1972). A computer program to determine the spectrum and a dispersion characteristic of a transient seismic signal, UKAEA AWRE Report No. 0-48/72 (HMSO).

Burton, P., Xu, Y. \& Hall, T.R. (2019). Tectonics, Seismology and Seismic Hazard, in "The Mw 7.8 Gorkha, Nepal Earthquake of 25 April 2015, A Field Report by EEFIT”, Earthquake Engineering Field Investigation Team, Institution of Structural Engineers, London, pp 12-34. http://www.eefit.org.uk

Burton, P. W. (1974). Estimations of $\mathrm{Q}^{-1}$ (f) from seismic Rayleigh waves. Geophysical Journal of the Royal Astronomical Society, 36, 167-189.

CalTech, (2012). Schuster Spectrum, http://www.tectonics.caltech. edu/resources/schuster_spectrum/, visited 3.3.2019.

CEA (China Earthquake Administration). (1999). Catalogue of Modern Earthquakes in China. Science and Technology Press.

Christiansen, L. B., Hurwitz, S., \& Ingebritsen, S. E. (2007). Annual modulation of seismicity along the San Andreas Fault near Parkfield, CA. Geophysical Research Letters, 34, L04306. https://doi.org/10.1029/2006GL028634

Cooley, J. W., \& Tukey, J. W. (1965). An algorithm for the machine calculation of complex Fourier series. Mathematics of Computation, 19(90), 297-301. https://doi.org/10.2307/2003354

Den, Q., Ma, J., \& Du, P. (2014). Seismic activities and earthquake potential in the Tibetan plateau. Chinese Journal of Geophysics, 57(7), 2025-2042.

Dutilleul, P., Johnson, C. W., Bürgmann, R., Wan, Y., \& Shen, Z.K. (2015). Multifrequential periodogram analysis of earthquake occurrence: An alternative approach to the Schuster spectrum, with two examples in central California. Journal of Geophysical Research: Solid Earth, 120, 8494-8515. https://doi.org/10.1002/ 2015JB012467

Farge, M. (1992). Wavelet transforms and their applications to turbulence. Annual Review of Fluid Mechanics, 24, 395-457.

Grossman, A., \& Morlet, J. (1984). Decomposition of hardy functions into square integrable wavelets of constant shape. SIAM Journal on Mathematical Analysis, 15(4), 723-736.

Lorito, S., Giberti, G., Siniscalchi, A., \& Iorio, M. (2003). Wavelet analysis on paleomagnetic (and computer simulated) VGP time series. Annual of Geophysics, 46, 573-588.

Makropoulos, K. C., \& Burton, P. W. (1983). Seismic risk of circum-Pacific earthquakes. I: Strain energy release. Pure and Applied Geophysics, 121, 247-267. 
Schuster, A. (1897). On lunar and solar periodicities of earthquakes. Proceedings of Royal Social London, 61, 455-465.

Schuster, A. (1898). On the investigation of hidden periodicities with application to a supposed 26-day period in meteorological phenomena. Terrestrial Magnetism, 3, 13-41. https://doi.org/10. 1029/TM003i001p00013

Torrence, C., \& Compo, G. P. (1998). A practical guide to wavelet analysis. Bulletin of the American Meteorological Society, 79(1), 61-78.

USGS. (2002). Introduction-Earthquake Science Center-USGS: Earthquake magnitude, intensity, energy, power law relations and source mechanism (by Kayal, J.R.). http://escweb.wr.usgs. gov/share. https://escweb.wr.usgs.gov/share/mooney/Sril-II3.pdf

USGS. (2014). Seismicity of the earth 1900-2010, Himalayan and vicinity, Open-file Report, 2010-1083-J, version 1, http://pubs. usgs.gov

USGS. (2017). https://earthquake.usgs.gov/

Xu, Y. (1992). A study on characteristics of information dimension D1 of the temporal and spatial distributions of earthquakes in an active fault zone. Acta Seismologica Sinica, 5, 389-398.
Xu, Y., \& Burton, P. W. (1997). Microearthquake swarms: Scaling and lacunarity. Geophysical Journal International, 13, F1-F8.

Xu, Y., \& Burton, P. W. (1999). Spatial fractal evolutions and hierarchies for microearthquake in central Greece. Pure and Applied Geophysics., 154, 73-99.

Xu, Y., \& Burton, P. W. (2006). Time varying seismicity in Greece: Hurst's analysis and Monte Carlo simulation applied to a new earthquake catalogue for Greece. Tectonophysics, 423, $125-136$

Xu, Y., \& Burton, P. W. (2014). Survival of seismogenesis: Cox proportional hazard model of large earthquake swarms: In Indonesia. Seismological Research Letters, 4, 794-800.

Xu, Y., Burton, P. W., \& Tselentis, G.-A. (2003). Regional seismic hazard for Revithoussa, Greece: An earthquake early warning Shield and selection of alert signals. Natural Hazards and Earth System Sciences, 3, 757-776.

Yin, J., Song, Z., Xue, Y., Liu, J., Zhang, G., \& Zhu, Y. (2012). Analysis on global huge earthquake activity. Acta Seismologica Sinica, 340, 191-201.

(Received May 3, 2020, revised July 11, 2021, accepted July 31, 2021, Published online September 1, 2021) 